\title{
The effect of growth factors on induction of mesenchymal stem cell to the skeletal muscle cells
}

\author{
Dogan $\mathrm{B}^{1}$, Kaan $\mathrm{D}^{2}$, Ulger $\mathrm{H}^{3}$ \\ Genome and Stem Cell Center, Erciyes University, Kayseri, Turkey.drdlkkaan@gmail.com
}

\begin{abstract}
OBJECTIVES: The objective of this study was to evaluate the effect of IGF1 and FGF2 growth factors on the differentiation of human adipose tissue-derived mesenchymal stem cells (MSCs) into skeletal muscle cells. METHODS: MSCs were divided into four groups. Group I (control group) was incubated only in myogenic medium, group II was incubated by adding $100 \mathrm{ng} / \mathrm{ml}$ FGF2 to the myogenic medium, group III was incubated by adding $20 \mathrm{ng} / \mathrm{ml}$ IGF1 to the myogenic medium, group IV was incubated by adding $100 \mathrm{ng} / \mathrm{ml}$ FGF2 and $20 \mathrm{ng} / \mathrm{ml} \mathrm{IGF1} \mathrm{to} \mathrm{the} \mathrm{myogenic} \mathrm{medium.} \mathrm{Cells} \mathrm{dyed} \mathrm{with} \mathrm{MyoD1} \mathrm{antibodies} \mathrm{were} \mathrm{analyzed} \mathrm{by} \mathrm{flow}$ cytometry so as to determine the myogenic differentiation on day 28.

RESULTS: It was confirmed that $11.5 \%$ of the control group, $39.2 \%$ of the FGF2 group, $23.1 \%$ of the IGF1 group, and $39.3 \%$ of the IGF1-FGF2 group showed differentiation.

CONCLUSION: Our results show that IGF1 and FGF2 have a positive contribution to myogenic differentiation of MSCs. They contribute to the studies related to muscle diseases and their treatment by the fact that growth factors support the feature of regeneration capacity and differentiation (Tab. 2, Fig. 7, Ref. 23). Text in PDF www.elis.sk

KEY WORDS: stem cell, myogenic differentiation, IGF, FGF.
\end{abstract}

\section{Introduction}

Stem cells are cells which could be priors of non-specialized cell types (1), they regenerate, and transform into different types of cells (2). There are three main features of stem cells that are still functionally undifferentiated, and potentially heterogeneous, namely self-renewal, pluripotency (3) and plasticity (differentiation) (4). MSCs are the most commonly used cell types in cellular therapies both in clinical trials and experimental studies (3).

Some of the studies have reported that insulin-like growth factors (IGF1 and IGF2) help muscle hypertrophy while both cytokines provide proliferation and differentiation of satellites $(5,6$, 7). In addition to insulin-like growth factors, the fibroblast growth factor-2 (FGF2) has been reported to significantly increase the growth rate and life of MSC in monolayer cultures (8). In experimental studies, it has been shown that FGF2 and IGF1 stimulate the proliferation of myogenic precursor cells (9). These results suggest that other growth factors such as FGFs play an important role in self-regeneration.

Recent studies have shown that different muscle stem development programs and/or progenitor cells and different muscle stems

${ }^{1}$ Institution of Health Sciences Erciyes University, Kayseri, Turkey, ${ }^{2}$ Genome and Stem Cell Center, Erciyes University, Kayseri, Turkey, and ${ }^{3}$ Medical Faculty, Department of Anatomy, Erciyes University, Kayseri, Turkey Address for correspondence: D. Kaan, PhD, Genome and Stem Cell Center, University of Erciyes Kayseri, Turkey, Kayseri, 38039, Turkey. Phone: +90.507 .0035838$ with genetic requirements are important for the production and/or regeneration of various muscles (10). In a study, in order to compensate for muscle loss in muscular dystrophy, induced pluripotent stem cells were transformed into skeletal muscle cells by using medium supported with fibroblast growth factor-2 (FGF2) and N2 (neurobasal media) (11). After these cells had been transplanted intramuscularly into the mouse model of muscular dystrophy, at a 24-week follow-up, adult myogenic cells were detected in the damaged area and it was observed that the muscle system was supported while there was no new muscle destruction in the long term (11). The aim of this study was to determine the effects of these growth factors on myogenic differentiation with the support of adipose tissue-originated MSCs, IGF1 and FGF2, which are frequently preferred in skeletal-muscle system studies and tissue engineering applications in the literature.

\section{Materials and method}

This study was approved by Erciyes University, Clinical Research Ethics Committee (Date: 15.09.2017, Study number: 418). The study was performed at Betül-Ziya Eren Genome and Stem Cell Center (GENKÖK).

\section{Mesenchymal stem cell culture from adipose tissue}

Cells are obtained from healthy women volunteers who were 18 years old or older, at Erciyes University Genome and Stem Cell Center (GENKÖK), Stem Cell Research and Development Laboratory. The cells were cultured in DMEM-low (Capricorn 


\section{3-857}

Scientific) containing $10 \%$ fetal bovine serum (FBS) (Sigma) $1 \%$ Pen-strep (10 Units / L penicillin and $10 \mu \mathrm{g} /$ L streptomycin, Gibco) $1 \mathrm{~g} / \mathrm{L}$ glucose. The cells were passaged at a density of $70-80 \%$.

\section{Flow cytometry analysis}

MSCs were collected and suspended in their culture media at a density of $1 \times 10^{6}$ cells $/ \mathrm{ml}$. Immune phenotyping was performed on FACS Canto II device by using Mouse IgG2b with FITC Mouse Anti-Human CD90, PE Mouse Anti-Human CD44, APC Mouse Anti-Human CD73, PerCP-Cy TM 5.5 Mouse Anti-Human CD105 positive markers and CD34 PE, CD11b PE, CD19 PE, CD45 PE, HLA-DR PE negative markers (Becton Dickinson, $B D$ ).

Transformation of mesenchymal stem cells into skeletal muscle cells

The myogenic medium was prepared with $50 \mu \mathrm{M}$ hydrocortisone (Sigma H0888), $0.1 \mu \mathrm{M}$ dexamethasone (Sigma D4902), $5 \%$ fetal bovine serum (Sigma) in total $20 \mathrm{ml}$ by using DMEM low (Capricorn Scientific) as a complement. Cells were incubated, namely group I cells (control group) only in myogenic medium, group II cells by adding $100 \mathrm{ng} / \mathrm{ml} \mathrm{FGF2} \mathrm{(Sigma} \mathrm{F0291)} \mathrm{in} \mathrm{myo-}$ genic medium, group III cells by adding $20 \mathrm{ng} / \mathrm{ml} \mathrm{IGF1} \mathrm{(sigma}$ I3769) in myogenic medium and group IV cells by adding 100 $\mathrm{ng} / \mathrm{ml} \mathrm{FGF2}$ and $20 \mathrm{ng} / \mathrm{ml}$.

\section{Intracellular staining (ICC) and flow cytometry analysis}

The cells were fixed with $100 \mu$ of $4 \% 2 \%$ formaldehyde for $10 \mathrm{~min}$, then washed (with staining buffer) and permeabilized with methanol for $30 \mathrm{~min}$ on ice. Then they were stained with primary anti MyoD1 (Abcam ab126726) antibody followed by goat polyclonal secondary antibody (Abcam) for 30 minutes.

\section{Statistical analysis}

Analyses were conducted using TURCOSA (Turcosa Analytics Ltd. Co., Turkey) statistical software (https://turcosa.com.tr/). Levene's test was used for evaluating the homogeneity of variances. One-way ANOVA test was used to compare the differences among groups for continuous variables. A p-value lower than 0.05 was considered statistically significant.

\section{Results}

\section{Characterization of mesenchymal stem cells}

The flasks with the cells were controlled at the end of day 4 to determine the presence of growth (Fig. 1A). At the end of the day 8 , the plate-base cell density was observed to be $80-90 \%$ in the re-examined flasks (Fig. 1B). Our cells were considered to be mesenchymal stem cells because upon microscopic examination, the cells were morphologically seen as fusiform-shaped, spindleshaped and fibroblast-like cell assemblies.

When the surface marker expressions of mesenchymal stem cells were evaluated by flow cytometry, it was determined that they positively expressed $95.59 \%$ of CD $44,92.38 \%$ of CD $73,99.86 \%$ of CD90, $99.78 \%$ of CD105 markers (Fig. 2), and there was no expression of CD45, CD34, CD11b, CD19 and HLA-DR negative cocktail.
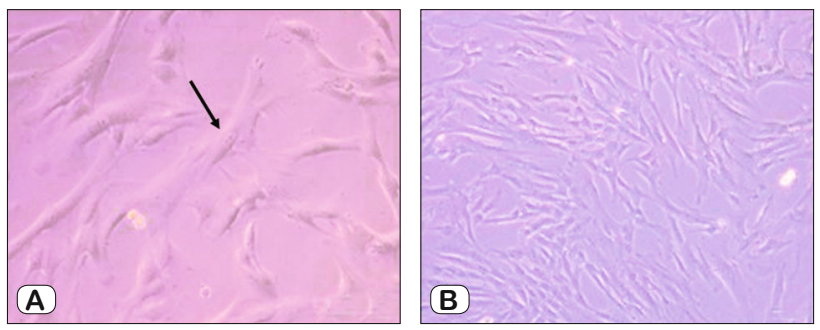

Fig. 1. On day 4 of the cell culture, cells attached to the bottom of the flask showing fibroblast-like morphology (A); Microscopic view of human adipose-derived MSCs on day 8 of sowing (B).
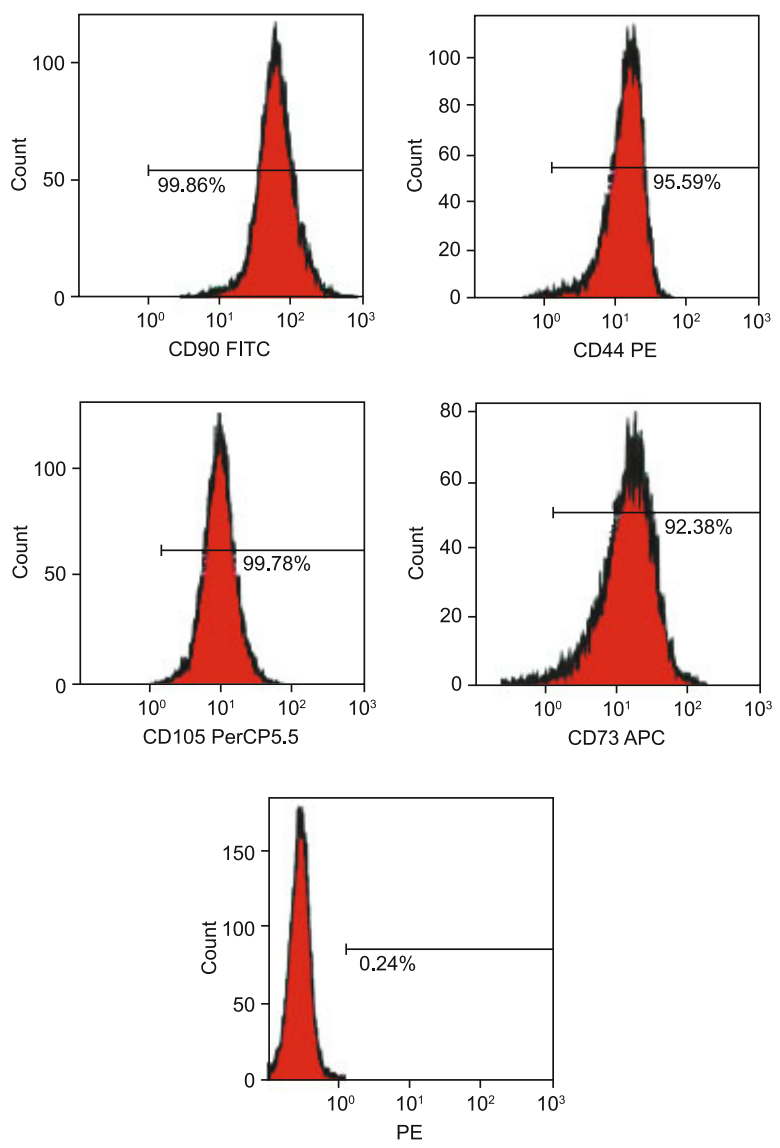

Fig. 2. Immunophenotyping of human adipose-derived stem cells by flow cytometry.

Induction of mesenchymal stem cells into skeletal muscle cells

Microscopic examination on day 7 after sowing revealed that fibroblast-like MSCs underwent deformation and exhibited spindle-shaped or polygonal morphology. When the groups were examined at the end of week 1, it was observed that the change was started in the cells of the control group incubated in myogenic medium. In the IGF1 group, it was observed that change started with the addition of myogenic medium and IGF1. In the FGF2 group, the change was observed with the addition of myogenic medium and FGF2. In the FGF2 + IGF1 group, it was observed 


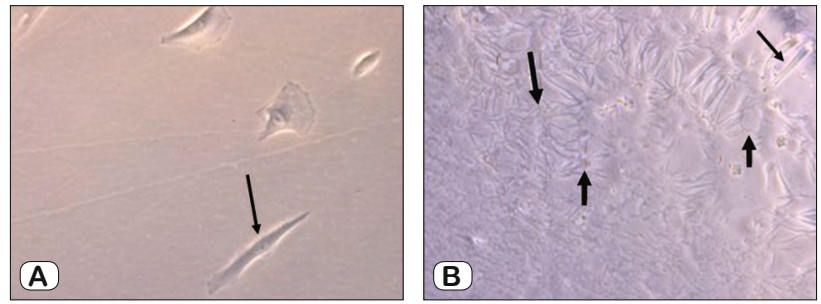

Fig. 3. Microscopic images of IGF1 + FGF2 group after incubation with adipose tissue-derived mesenchymal stem cells with conditional (myogenic) medium at the end of week one. Thin arrow spindle shaped MSC form (A); Microscopic images of IGF group at the end of week 4 after incubation with adipose tissue-derived mesenchymal stem cells with conditional (myogenic) medium. Thick arrow: myoblast formation, thin arrow: myotube formation (B).
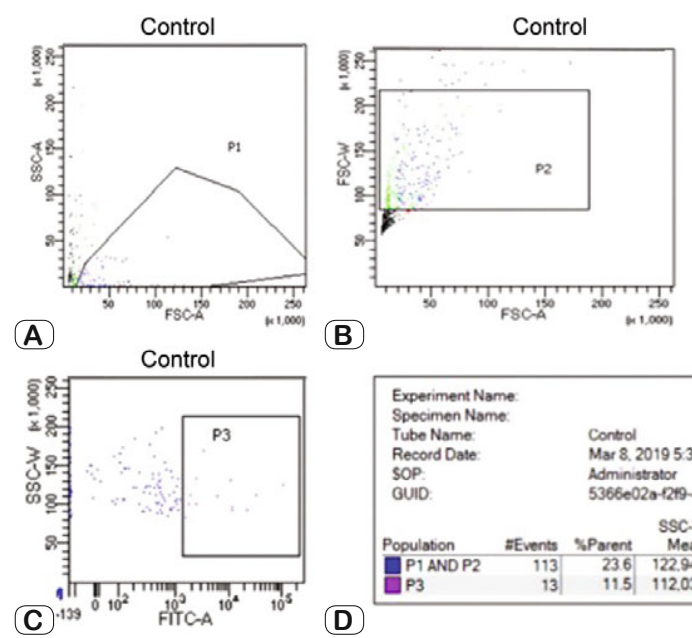

(B)

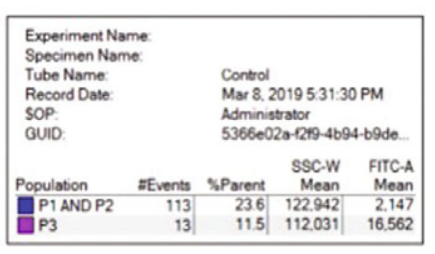

(D)

Fig. 4. Evaluation of control group by using flow cytometry device. P1 gate is a collection of alive cells (A); Gate P2, single cells (B); P3 gate, cells showing myogenic differentiation $(\mathrm{C})$; expression of the values in the control group (D).
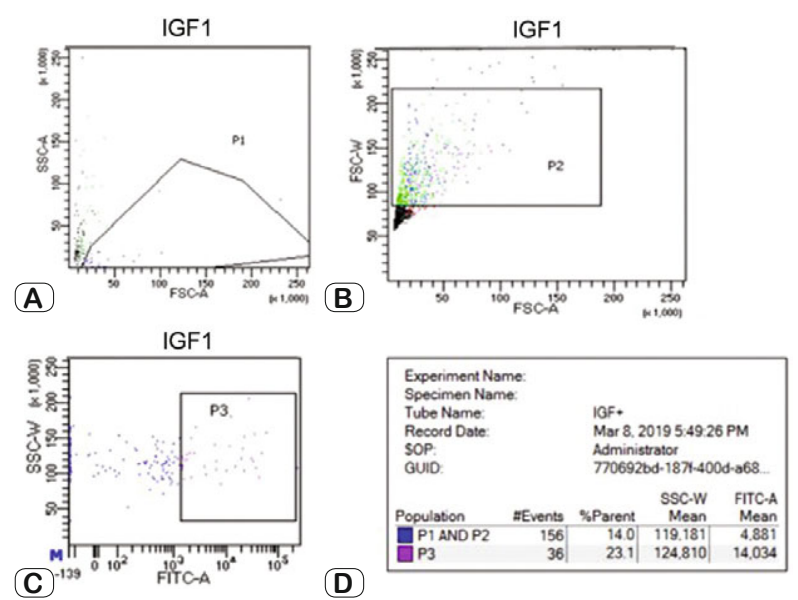

Fig. 5. Evaluation of IGF group by using flow cytometry device. P1 gate is a collection of alive cells (A); Gate P2, single cells (B); gate P3, cells showing myogenic differentiation (C); Expression of values in group IGF1 (D). that after the addition of myogenic medium and FGF2 + IGF1, the mesenchymal stem cells separated and became singular (Fig. 3A).

Upon the microscopic examination performed at week 2 of cell cultivation, the decrease in plate-base cell density was observed more prominently in IGF1 and FGF2 groups as compared with that performed at week 1 .

At week 3, the microscopic examination in IGF1 group showed an increase in regular, unique and consistent lines in cell culture. When the plate-base cell density was examined compared to the second week, it was observed that the cells fused and the cells' density increased. Upon the microscopic examination at week 4 of cultivation, the initially spindle cells in the cell culture fused and completely transformed while acquiring a myoblast shape. Even a step ahead of the formation, albeit small, myotube was observed
(A)
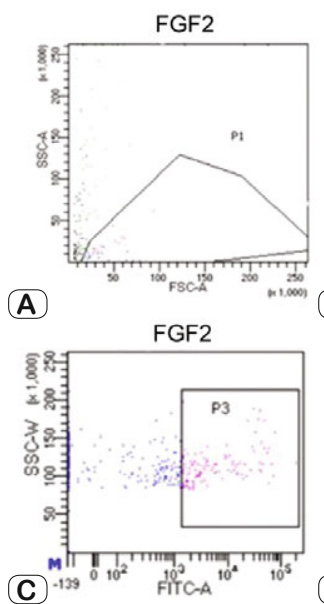

(B)

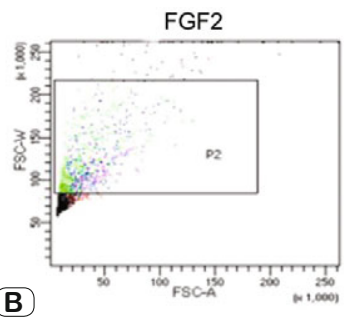

(D)

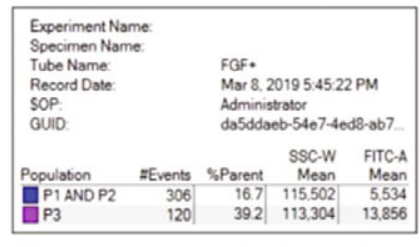

Fig. 6. Evaluation of FGF2 group by using flow cytometry. P1 gate is a collection of alive cells (A); Gate P2, single cells (B); gate P3, cells showing myogenic differentiation (C); Expression of values in the FGF2 group (D).
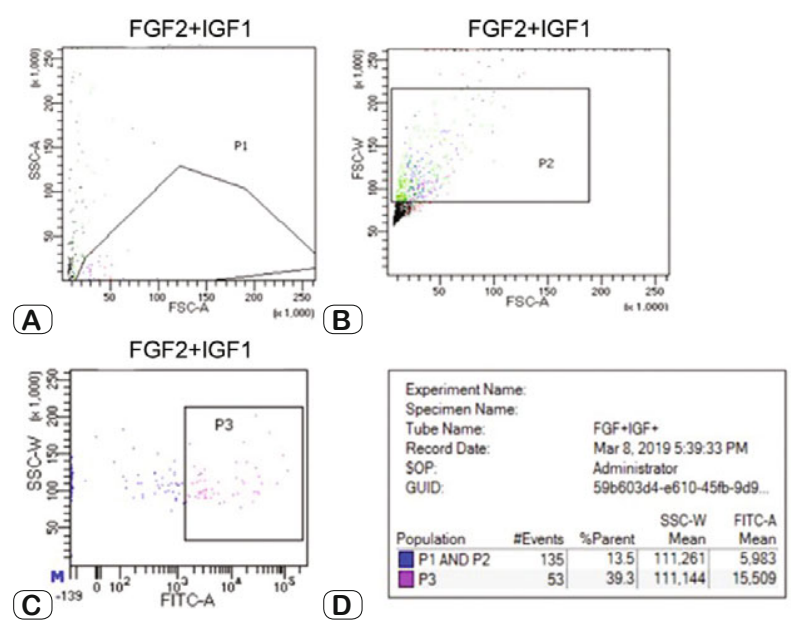

Fig. 7. Evaluation of IGF1 + FGF2 group by using flow cytometry. $P 1$ gate is a collection of alive cells (A); Gate P2, single cells (B); gate $P 3$, cells showing myogenic differentiation (C); Expression of values in group IGF1 + FGF2 (D). 
853-857

(Fig. 3B). At the end of week 4, the change in IGF1 group was microscopically observed to be more intense as it covered the whole plate base. It was also observed that the line-formed cells were structurally thinner.

When the mesenchymal stem cells originating from the myogenic orientation adipose tissue were examined under invert microscope, it was observed that the morphology of the cells changed and the form of cell groups started to change beginning with week 2. This was determined by looking at MyoD syntheses.

\section{Interpretation of flow cytometry analysis data results}

The differentiation of MSCs into skeletal muscle cells by induction was determined by flow cytometry using intracellular cellular staining with MyoD1.

According to the results of flow cytometry evaluation in the P1 gate, the cell population stained intracellularly (Figs 4A, 5A, 6A, $7 \mathrm{~A}$ ), in the $\mathrm{P} 2$ gate, a population of non-touching, non-adherent, stained and unstained single cells (Figs 4B, 5B, 6B, 7B), and in the $\mathrm{P} 3$ gate, a population of alive cells (Figs 4C, 5C, 6C, 7C) were shown for all groups.

Up to $11.5 \%$ of the total alive cell population was shown to present myogenic differentiation in the control group (Fig. 4D). In the IGF group, $23.1 \%$ of the total alive cell population showed myogenic differentiation (Fig. 5D). In the FGF group, $39.2 \%$ of the total alive cell population showed myogenic differentiation (Fig. 6D). In the IGF + FGF group, $39.3 \%$ of the total alive cell population showed myogenic differentiation (Fig. 7D, Tab. 1).

\section{Statistical analysis results}

In the study, $p<0.005$ was considered statistically significant, and the difference between the groups was found to be significant (Tab. 2).

In myogenic medium groups, the expressions in $\mathrm{P} 3$ gate was increased compared to the control group. The differentiation was less abundant in IGF1 group compared to FGF2 and IGF1 + FGF2 groups. The levels of increase in FGF2 and IGF1 + FGF2 groups were similar. In both cell groups, both the increase in the number of cells and the rates of differentiation were higher than in the other groups.

\section{Discussion}

Growth factors play an important role in the transformation of stem cells into different tissues. The growth factors determine the functions of the proteins involved in the growth, division or differentiation of the cell according to its need during its survival. It can be produced naturally in our bodies if needed throughout our lives. For example, growth factors provide repair if the cell needs repair and there is enough protein in our body, by directing them.

Tab. 1. The comparison of flow cytometry data per group.

\begin{tabular}{lcccc}
\hline Flow cytometry & $\begin{array}{c}1^{\text {st }} \text { group } \\
\text { control group }\end{array}$ & $\begin{array}{c}2^{\text {nd }} \text { group } \\
\text { IGF group }\end{array}$ & $\begin{array}{c}3^{\text {rd }} \text { group } \\
\text { FGF group }\end{array}$ & $\begin{array}{c}4^{\text {th }} \text { group } \\
\text { FGF+IGF group }\end{array}$ \\
\hline P3 (Differentiating cells) & $11.5 \%$ & $23.1 \%$ & $39.2 \%$ & $39.3 \%$ \\
\hline
\end{tabular}

Tab. 2. The mean of the myogenic differentiating alive cell populations per group.

\begin{tabular}{lc}
\hline Group $(\mathrm{n}=24)$ & Mean \pm SD \\
\hline Control & $11.5 \pm 0.28^{\mathrm{a}}$ \\
IGF1 & $23.1 \pm 0.21^{\mathrm{b}}$ \\
FGF2 & $39.2 \pm 0.17^{\mathrm{c}}$ \\
IGF1 +FGF2 & $39.3 \pm 0.32^{\mathrm{c}}$ \\
P & $0.005^{-}$ \\
\hline \multicolumn{2}{l}{ The same letters represent similarity between the groups, while the differing letters }
\end{tabular}
indicate a difference

If there is no protein, it becomes impossible to eliminate tissue losses which thus cannot be repaired. At this point it is possible to benefit from stem cells which represent a new hope of our time.

Studies reveal the effect of growth factors on skeletal muscle formation and regeneration. It has been reported that specific combinations of muscle-regulating transcription factors can be generated by incorporating growth factors such as FGF2 into the medium (12). FGF2 has been reported to increase muscle regeneration (13) in dystrophic muscle in mice, whereas FGF2 has been reported to provide a significant reduction in the size of the ischemic region in coronary patients (14). FGFs are critical factors for controlling the proliferation and differentiation of myogenic progenitors and myoblasts during myogenesis. FGF2 is known to inhibit the differentiation of myogenic progenitors into myotubes, which implies that FGF2 can be used to retain progenitors at an immature stage. Interestingly, in murine myoblast $\mathrm{C} 2 \mathrm{C} 12$ cells, an inhibition of the mitogen-activated protein kinase (MAPK) pathway below FGF has been reported to increase the expression of MyoD, myogenin and MSC, and lead to further myoblast fusion (15). The use of bFGF, the most common growth supplement when preparing MSC culture, greatly increases the rate of proliferation, while also increasing human leukocyte antigens (HLA) class I and inducing low HLA expression. However, this regulation not only makes allogeneic $\mathrm{T}$ cell responses in vitro significant, but also bFGF-cultured MSCs show an increase in immunosuppressive potential in vivo. On the other hand, the addition of bFGF affects the differentiation capacity of MSC, promotes correct differentiation of the osteogenic lineage, and has been reported to limit the neurogenic potential (16).

In addition to FGF2, growth factors such as IGF1 and transforming growth factor have also been implicated in regulating the proliferation and differentiation of satellite cells (17). Researchers reported that IGF1, another growth factor, plays an important role in muscle development proliferation, is involved in degeneration of skeletal muscles, and may improve some muscle destruction diseases by reducing the effect of myostatin, which inhibits myogenesis, on muscle development (18). It has been shown that IGF1 supports the differentiation of skeletal muscle cells (19). Tollefsen et al., who thought that the tasks of IGF1 and IGF2 in skeletal muscle and myoblast cell series were complex, stated that both growth factors stimulate cellular proliferation and differentiation (20). 
The addition of hydrocortisone to the culture medium showed that the total cell yield decreased by 2 -fold, but the cloning efficiency increased by 2-3-fold (21).

It has been proposed that MyoD myogenic cells represent an intermediate step between myogenic stem cell and myogenic precursor cell (22). Although our study results are similar to the results of studies in literature, by adding the FGF2 growth factor to the conditional medium in the myogenic differentiation process, the morphologic differentiation was shorter in comparison to the effect of IGF growth factor. In addition, as a result of the intracellular cellular staining with MYOD1, it was observed that the transformed cell population was higher.

In the control group with dexamethasone and hydrocortisone which are synthetic glucocorticoid biomolecules used jointly in differentiation studies, the percentage of myogenic differentiation was lower in the group with FGF2 and IGF growth factors. FGF growth factor is one of the key actors showing numerous functions including cell proliferation, differentiation, survival and mobility. In addition to our study (23), it was shown that FGF2 positively influenced differentiation. It was shown that IGF1 and FGF2 positively affect myogenic differentiation. However, it was concluded that the expected positive correlation was not shown in concomitant use and that FGF2 alone could be sufficient for differentiation process.

\section{Contribution to the field}

This study shows that supporting the regeneration capacity and differentiation of stem cells with growth factors, will contribute significantly to the treatment of many specific diseases. We hope to bring solutions to the problems in this field.

\section{References}

1. Nayak A, Siju P, Kanani A, Bhargav P. Function of stem cells and their future roles in healthcare. Internat J Pharm 2014; 1: 2852-2895.

2. Şahin F, Saydam G, Omay SB. Kök hücre plastisitesi ve klinik pratikte kök hücre tedavisi. Türk Hemalotoji-Onkoloji Dergisi 2005; 1 (15): 48-56.

3. Matur I, Solmaz S. Kök hücre üretiminde güncel yaklaşimlar. Arşiv 2011; 20: 168.

4. Ateş U. Kök hücreyi taniyalim. FNG\&Bilim Tip Transplantasyon Dergisi 2016; 1 (1): 19-28.

5. D'Amario D, Cabral-Da-Silva M, Zheng $\mathbf{H}$ et al. The IGF-1 receptor identifies a pool of human cardiac stem cells with superior therapeutic potential for myocardial regeneration. Circulat Res 2011; 108 (12): $1467-1481$.

6. Huang Y, Qiu R, Mai W et al. Effects of insulin-like growth factor-1 on the properties of mesenchymal stem cells in vitro. J Zhejiang Univ Sci B 2012; 13 (1): 20-28.

7. Ural A. Embriyonel ve mezodermal kök hücreler, Gülhane Askeri Tip Akademisi, Hematoloji Bilim Dali 2017.
8. Tsutsumi S, Shimazu A, Miyazaki K et al. Retention of multilineage differentiation potential of mesenchymal cells during proliferation in response to FGF. Biochem Biophys Res Comm 2001; 413-419.

9. Deasy Z, Peterson Q, Greenberger JS, Huard J. Mechanisms of muscle stem cell expansion with cytokines. Stem Cells 2002; 50-60.

10. Kang SB, Lee HN, Lee JY, Park JS, Lee HS, Lee JY. Sphincter contractility after muscle-derived stem cells autograft into the cryoinjured anal sphincters of rats. Internat Urogynecol J 2008; 51 (9): 1367-1373.

11. Shelton M, Metz J, Liu J, Carpenedo RL, Demers SP, Stanford WL, Skerjanc I. Derivation and expansion of pax7-positive muscle progenitors from human and mouse embryonic stem cells. Stem Cell Reports 2014; 3: 516-529.

12. Gutiérrez J, Brandan E. A Novel mechanism of sequestering fibroblast growth factor2 by glypican in lipid rafts. Allowing skeletal muscle differentiation. 2010; 30 (7): 1634-1649.

13. Cessna J, Zhou H, Perkins SL et al. Are myogenin and MyoD1 expression specific for rhabdomyosarcoma? A study of 150 Cases, with emphasis on spindle cell mimics. Am J Surg Pathol 2001; 25 (9): 1150-1157.

14. Presta M, Dell'Era P, Mitola S, Moroni E, Ronca R, Rusnati M. Fibroblast growth factor/fibroblast growth factor receptor system in angiogenesis. Cytokine Growth Factor Rev 2005; 16 (2): 159-178.

15. Jiwlawat N, Lynch E, Jeffrey J, Dyke J, Suzuki M. current progress and challenges for skeletal muscle differentiation from human pluripotent stem cells using transgene-free approaches. Hindawi Stem Cells International Volume 2018; 18.

16. Sotiropoulou S, Panagiota A, Perez A, Salagianni M, Constantin N, Baxevanis C, Papamichail M. Characterization of the optimal culture conditions for clinical scale production of human mesenchymal stem cells. Stem cells 2004; 24 (2): 462-471.

17. Tortorella LL, Milasincic D, Pilch PF. Critical proliferation-independent window for basic fibroblast growth factor repression of myogenesis via the p42/p44 mapk signaling pathway. J Biol Chem 2001; 276 (17): 13709-13717.

18. Gehmert S, Wenzel C, Loibl M, et al. Adipose tissue-derived stem cell secreted igf-1 protects myoblasts from the negative effect of myostatin. BioMed Res Internat 2014: 9.

19. Ogata T, Teshima $T$, Inaoka $M$ et al. Carbon ion irradiation suppresses metastatic potential of human non-small cell lung cancer a549 cells through the phosphatidylinositol-3-kinase/akt signaling pathway. $\mathrm{J}$ Radiation Res 2011: 374-379.

20. Tollefsen SE, Thompson K, Petersen DJ. Separation of the high affinity insulin-like growth factor i receptor from low affinity binding sites by affinity chromatography. J Biol Chem 1987; 262: 16461-1646.

21. Shipunova N, Petinati N, Drize N. Effect of hydrocortisone on multipotent human mesenchymal stromal cells. Bull Exp Biol Med 2013; 155 (1): $159-163$.

22. Sabourin L, Girgis-Gabardo A, Seale P, Asakura A, Rudnicki M. Reduced differentiation potential of primary myod $-/-$ myogenic cells derived from adult skeletal muscle. J Cell Biol 1999; 144 (4): 631-643.

23. Kashiwakura I, Takahashi TA. Fibroblast growth factor and ex vivo expansion of hematopoietic progenitor cells. Leuk Lymphoma 2005; 46 (3): 329-333. 